\title{
Early development and regression in Rett syndrome
}

\section{AUTHORS}

Joanne Y L Lee BPsych(Honours), MPsych(Clinical) ${ }^{1}$, Helen Leonard $\mathrm{MBChB}^{2}, \mathbf{J a n} \mathbf{P}$ Piek $\mathrm{PhD}^{1}$, Jenny Downs $\mathrm{PhD}^{2,3}$

\section{INSTITUTIONAL AFFILIATIONS}

${ }^{1}$ School of Psychology and Speech Pathology and Curtin Health Innovation Research Institute, Curtin University; ${ }^{2}$ Centre for Child Health Research, Telethon Institute for Child Health Research, University of Western Australia, Perth, Australia; ${ }^{3}$ School of Physiotherapy and Curtin Health Innovation Research Institute, Curtin University.

\section{CORRESPONDING AUTHOR}

Dr Helen Leonard

Telethon Institute for Child Health Research, Centre for Child Health Research, University of Western Australia, Perth, Western Australia, 6872

Telephone: +610894897790

Fax: +61 0894897700

Email: hleonard@ichr.uwa.edu.au

\section{CONFLICT OF INTEREST}

Each of the authors has no conflict of interest to report.

\section{ACKNOWLEDGEMENTS}

We wish to send our deepest thanks to all the mothers who participated in this research study: we truly appreciate the time they took to share their heartfelt stories. The authors would like to acknowledge the International Rett Syndrome Foundation (IRSF previously IRSA) for their ongoing support of the InterRett project and their continued encouragement of this international collaboration. The Australian Rett Syndrome Study was funded by the National Institutes of Health (5R01HD043100-05) and also by the National Health and Medical Research Council (NHMRC) project grant 303189 for certain clinical aspects. Helen Leonard was previously funded by a NHMRC programme grant 353514 . Her current funding is from an NHMRC Senior Research Fellowship 572568.

\section{Keywords}

Rett syndrome, regression, development, autistic symptoms, $M E C P 2$ 


\begin{abstract}
This study utilised developmental profiling to examine symptom presentation in 14 girls with genetically confirmed Rett Syndrome and whose family was participating in the Australian Rett Syndrome or InterRett database. Regression was mostly characterised by loss of hand and/or communication skills (13/14) except one girl demonstrated slowing of skill development. Social withdrawal and inconsolable crying often developed simultaneously (9/14) with social withdrawal of shorter duration than inconsolable crying. Previously acquired gross motor skills declined in just over half of the sample (8/14), mostly observed as a loss of balance. Early abnormalities such as vomiting and strabismus were also seen. Our findings provide additional insight into the early clinical profile of Rett syndrome.
\end{abstract}




\section{Introduction}

Rett syndrome is a rare neurodevelopmental disorder with a prevalence of approximately 1 per 9,000 live-born females in Australia (1). Established clinical criteria include developmental regression (2) and diagnosis is usually confirmed by testing of the MECP2 gene. Developmental deviations prior to regression, have been described in a population-based study (3) and observed in infant videos (4). Developmental regression occurred at a mean age of 19.3 months in a sample of US and Australian cases $(n=299)$ born since 1999 (5). Those with earlier regression were less likely to learn to walk or talk whereas those with later regression were more likely to do so. Relationships between the early clinical features of Rett syndrome and specific MECP2 mutations were also confirmed (5). Regression is usually followed by a period of stability when the child re-engages with the environment and learning is again possible (6).

Despite established clinical criteria and genetic testing, there is a lack of clinical knowledge about the regression period especially when early presentation can be variable. Previous studies lacked genetic information $(7,8)$ or included cases that were adults at time of data collection (7). The current study therefore sought to describe developmental pathways of the pre-regression and regression period in depth in a small genetically characterised sample of young girls with Rett syndrome.

\section{Materials and Methods}

Ethics approval was obtained from Curtin University. Interviews were conducted with 14 mothers who were participating in the Australian Rett Syndrome Database $($ ARSD)(9) $(n=3)$ or InterRett database (10) $(n=11)$. Median age at interview of cases was four years (range 2-5 years). All had a clinical diagnosis of Rett syndrome and a pathogenic MECP2 mutation: four p.R255X; three p.R133C; two each with p.R270X and p.T158M; and one each with a C-terminal deletion, p.R106W or p.R294X mutation. Median age of 
diagnosis was 24 months (range 19-42 months) (Table 1). Previous diagnoses included global developmental delay $(n=3)$, autism $(n=2)$ or pervasive developmental disorder not otherwise specified $(n=2)$. Abnormal EEG activity had been recorded for five girls and three mothers reported active seizures that were currently managed by anti-epileptic medications.

The interview schedule included questions about initial concerns; gross motor (e.g., sitting, crawling, walking), fine motor (e.g., hand function, stereotypies) and communication (e.g., speech, non-verbal communication) skills; symptoms of Rett syndrome (e.g., inconsolable crying, night laughing) and personal-social (e.g., autistic symptoms) aspects. Prior to interview, mothers reviewed infant records to facilitate better recall of events. Preexisting information (e.g., genetic mutation, age of diagnosis) was obtained from the ARSD and InterRett databases. Interviews were conducted by telephone and recorded. Mothers were requested to submit home videos or photos to assist with validation and seven provided materials. All photos and videos, some of which were serial, validated the findings. Interview recordings were transcribed and nine mothers completed the member-checking portion of the study. All data was used to construct the final developmental profiles as a timeline summarising the age of onset and duration of symptoms.

\section{Results}

The following observations are presented in broad chronological order and the themes and age of onset for each girl are shown in Table 1.

\section{Early concerns}

The median age of initial symptom presentation was 12 months (range 2 -34). The classic criteria of loss of hand or speech skills were the first identifiable sign of abnormality in four girls and the development of hand stereotypies in two. For two girls, the first identifiable sign of abnormality was the development of strabismus or crossed eyes occurring 
between 12 and 14 months. Two mothers reported severe vomiting as the first sign of abnormality. For both cases, the vomiting occurred prior to 6 months of age and remained severe (e.g., occurring daily) until approximately three years of age. For one of the girls, it was associated with severe reflux and for the other no diagnosis was made although one course of anti-reflux medication was trialled. The first symptoms for three girls were inconsolable crying and poor sleep and for one girl a persistent crick in the neck in combination with sudden left hand dominance and a mild strabismus. These were accompanied by early general concerns including the girls being placid in infancy (7/14), poor head control (4/14), and early developmental delay (7/14). See Table 2 for the initial concerns, ages of onset, and illustrative quotes.

\section{Regression}

The median age at onset of regression was 18 months (range 9-34) with the regression being 'rapid' or 'sudden' in eight and occurring 'slowly over time' in five girls. Seven experienced regression prior to or at 18 months of age: two with the mutation p.R255X, two p.T158M, one p.R106W, and two p.R270X. Of these, one walked independently. Six girls experienced regression later than 18 months of age: two with the mutation p.R255X, three with the mutation p.R133C and one p.R294X. Five of these were independently mobile. The $14^{\text {th }}$ case (C-terminal deletion) had learned to walk and although regression of hand and speech skills had not been observed, developmental progress in these domains was slower.

Ten girls lost previously acquired speech or language at a median age of 16 months (range 9-36). Some girls were described as going 'quiet', and, irrespective of their level of speech, were described as being 'less vocal'. Following regression, the majority did not use words although four used words inconsistently (i.e. occasionally and in isolation). In contrast, four girls did not experience a loss of speech: for three 'babble' was the highest speech level achieved while one girl had delayed speech acquisition but still retained over 50 words. 
At a median age of 18 months (range 10 to 36) 13 girls lost hand function skills such as the pincer grip, self-feeding skills, holding their bottle, pushing buttons, and picking up or carrying toys. Hand function was retained in one case with delayed development rather than regression of skills (C-terminal deletion).

Nine girls lost both speech and hand function skills and of those, six $(66.7 \%)$ lost speech skills prior to losing hand function skills.

\section{Hand stereotypies}

Hand stereotypies developed in all cases with onset at a median age of 15 months (range 9-33) and were often frequent and intense. Hand stereotypies developed prior to a loss of hand function in eight girls, after loss of hand function in three, and simultaneously in the remaining three.

\section{Social withdrawal, diminished eye contact and inconsolable crying}

Eleven girls developed autistic type symptoms of social withdrawal and diminished eye contact at a median age of onset of 15 months (range 9-36). In eight, symptoms were noticed contemporaneously with loss of speech and hand skills. At interview, ten of the 11 no longer displayed these symptoms, their median duration having been 5 months (range 3-23).

Eleven also experienced inconsolable crying, both during the day (8/14) and at night (9/14). The median age of onset was also 15 months (range 9-47) and median duration 25 months. Three girls were still experiencing inconsolable crying episodes at interview. Inconsolable crying developed simultaneous to loss of speech or hand function in 7/14 and with social withdrawal in 9/14. Only one girl (C-terminal deletion) had not presented with autistic type symptoms.

\section{Balance and walking}


Over the early developmental period, six learned to walk independently, two were able to take supported steps, and three were able to stand with support. At interview these skills remained and one additional girl was able to stand with support. Of those able to walk independently, three had a p.R133C mutation, one p.R270X, one p.R294X, and one had a Cterminal deletion. None of those with a p.R255X mutation was independently mobile.

Half of the girls experienced altered gross motor skills following regression, often a deterioration of balance and sometimes accompanied by an abnormal gait. Balance problems were observed not only in girls who were able to walk (5/6), but also those who were only able to take supported steps (1/2), stand with support (1/3), or sit independently (1/3). The median age of onset of gait and balance problems was 36 months (range 18-42), and was observed in two each with the mutations p.R270X, p.R255X and p.R133C and in the one with a C-Terminal deletion. Loss of gross motor skills was subtle, developing slowly over time.

\section{Discussion}

Consistent with Hagberg's staging model (6), regression in the current sample comprised a loss of previously acquired hand and speech skills, in addition to the development of hand stereotypies, social withdrawal and inconsolable crying. As in previous large genotype phenotype studies (5), earlier regression was observed in girls with the mutation types p.R255X and p.T158M who also experienced poorer gross motor development and were unable to walk independently. Regression after 18 months of age was observed in girls with the mutation types p.R133C and p.R294X. Hand stereotypies were often frequent and severe, consistent with literature in which the number and intensity of stereotypies were greater during the early years (11).

As with previous research (12), the girl with a C-terminal deletion had a milder clinical profile and no regression in hand or speech skills by time of interview (age 51 
months). The most plausible explanation is that this particular mutation is associated with the late regression variant $(2,12,13)$ and that earlier symptoms include delay rather than regression of skills.

As expected, social withdrawal and inconsolable crying occurred during regression (6). We found that the period of social withdrawal was short and ability to interact socially was regained quickly whilst inconsolable crying persisted for longer. With social withdrawal and a milder phenotype, some in our study had an earlier diagnosis of autism (14) although there was no evidence to suggest that these autistic symptoms persisted beyond the regression period. This was an extremely challenging time for families and strategies involving less physical contact such as playing a DVD or music were often more effective in calming their distressed child.

The early onset vomiting exhibited by two girls in our study was spontaneous and severe, and clinically confirmed as reflux in one. Gastrointestinal issues can occur early in Rett syndrome $(3,15)$ and our findings illustrate the potential for gastro-intestinal dysmotility to have early and dramatic effects. Strabismus or crossed eyes could have related to altered muscle tone, with 'unusual behaviour in the eyes' previously reported in the literature as an early symptom (15), and the girl with torticollis had additional neurological signs.

Soon after regression, there was often loss of balance consistent with the development of truncal ataxia and development of impaired gait (6). In another study ( $n=53)$, almost half of the girls experienced loss of motor skills during regression (7) although the findings were limited due to possible recall error (age range 2-44 years at time of study). Early gross motor development influences social and emotional development, non-verbal communication skills and spatial abilities (16). Hence, understanding the early gross motor profile may not only provide further insight into the underlying mechanisms of 'abnormal gait' but possibly also other features of Rett syndrome. 
The regression period is a difficult time for girls with Rett syndrome and their families, a time when worry, distress and confusion are compounded by lack of a definitive diagnosis. We utilised developmental profiling to explore this period with a comprehensive child development perspective. To minimise recall error, we restricted our sample to girls born after 2007 and requested that mothers review infant records prior to interview. Member checking of the interview transcripts increased the accuracy of the data. We acknowledge that there may be some recall bias in the mother's recollection of early developmental events. To reduce this, we validated our data using existing information in the ARSD and InterRett database and also home videos and photos. Our observations were consistent with previous genotype-phenotype relationships in Rett syndrome but our small sample size precluded statistical analyses of current data. Neurological examination findings would provide additional information in documenting the evolution of gross motor dysfunction.

The early clinical profile of Rett syndrome is complex and other signs often precede the main criteria. We have also illustrated variability in how hand and speech skills may be lost; the temporal relationships between social withdrawal and inconsolable crying; and how previously acquired gross motor skills may decline with loss of balance soon after regression. The clinical profile of RTT should not be characterised by the development of these features in isolation, but more so by how they emerge and interact.

\section{References}

1. Fehr S, Bebbington A, Nassar N, et al. Trends in the diagnosis of Rett syndrome in Australia. Pediatr Res. 2011 May 16;70:313-9.

2. Neul JL, Kaufmann WE, Glaze DG, et al. Rett syndrome: Revised diagnostic criteria and nomenclature. Ann Neurol. 2010;68:944-50.

3. Leonard H, Bower C. Is the girl with Rett syndrome normal at birth? Dev Med Child Neurol. 1998 Feb;40:115-21.

4. Einspieler C, Kerr AM, Prechtl HF. Is the early development of girls with Rett disorder really normal? Pediatr Res. 2005 May;57:696-700. 
5. Fehr S, Bebbington A, Ellaway C, et al. Altered Attainment of Developmental Milestones Influences the Age of Diagnosis of Rett Syndrome. J Child Neurol. 2011 Aug;26:980-7.

6. Hagberg B. Clinical criteria, stages and natural history. In: Hagberg B, editor. Rett Syndrome - Clinical and Biological Aspects. London: Mac Kieth Press; 1993. p. 4-20.

7. Charman T, Cass H, Owen L, et al. Regression in individuals with Rett syndrome. Brain Dev. 2002 Aug;24:281-3.

8. Witt-Engerstrom I. Rett syndrome: a retrospective pilot study on potential early predictive symptomatology. Brain Dev. 1987;9:481-6.

9. Leonard H. Rett's syndrome: opportunity for Australian study. Med J Aust. 1993;159:832-.

10. Fyfe S, Cream A, de Klerk N, et al. InterRett and RettBASE: International Rett Syndrome Association databases for Rett syndrome. J Child Neurol. 2003 Oct;18:709-13. 11. Carter P, Downs J, Bebbington A, et al. Stereotypical hand movements in 144 subjects with Rett syndrome from the population-based Australian database. Mov Disord. 2010 Feb 15;25:282-8.

12. Bebbington A, Percy A, Christodoulou J, et al. Updating the profile of C-terminal MECP2 deletions in Rett syndrome. J Med Genet. 2010 Apr;47:242-8.

13. Hagberg BA, Skjeldal OH. Rett variants: a suggested model for inclusion criteria. Pediatr Neurol. 1994;11:5-11.

14. Young D, Bebbington A, Anderson A, et al. The diagnosis of autism in a female: could it be Rett syndrome? Eur J Pediatr. 2008;167:661-9.

15. Leonard H, Moore H, Carey M, et al. Genotype and early development in Rett syndrome: the value of international data. Brain Dev. 2005 Nov;27 Suppl 1:S59-S68. 16. Campos JJ, Anderson DI, Barbu-Roth MA, et al. Travel Broadens the Mind. Infancy. 2000;1:149-219. 
Table 1: Descriptive details and age of onset (months) for each of the themes of the pre-regression and regression periods for each child

\begin{tabular}{|c|c|c|c|c|c|c|c|c|c|c|c|c|}
\hline Number & Mutation & $\begin{array}{l}\text { Birth } \\
\text { year }\end{array}$ & $\begin{array}{l}\text { Age at } \\
\text { interview } \\
\text { (months) }\end{array}$ & $\begin{array}{c}\text { First } \\
\text { RTT } \\
\text { symptom }\end{array}$ & $\begin{array}{l}\text { Onset of } \\
\text { regression }\end{array}$ & $\begin{array}{c}\text { Autistic } \\
\text { symptoms }\end{array}$ & $\begin{array}{l}\text { Inconsolab } \\
\text { le crying }\end{array}$ & $\begin{array}{l}\text { Loss hand } \\
\text { function }\end{array}$ & $\begin{array}{c}\text { Hand } \\
\text { stereotypies }\end{array}$ & $\begin{array}{l}\text { Loss of } \\
\text { speech }\end{array}$ & $\begin{array}{l}\text { Decline in } \\
\text { gross motor } \\
\text { skills }\end{array}$ & $\begin{array}{l}\text { Age at } \\
\text { diagnosis } \\
\text { (months) }\end{array}$ \\
\hline 1 & p.R255X & 2007 & 51 & 14 & 14 & 15 & 15 & 18 & 15 & 14 & 42 & 22 \\
\hline 2 & p.R255X & 2007 & 60 & 24 & 24 & - & 47 & 24 & 24 & - & - & 23 \\
\hline 3 & p.R255X & 2007 & 53 & 9 & 9 & 9 & 9 & 12 & 12 & 9 & 36 & 29 \\
\hline 4 & p.R255X & 2009 & 34 & 18 & 18 & 20 & 18 & 18 & 19 & 19 & - & 22 \\
\hline 5 & p.R133C & 2007 & 49 & 15 & 34 & - & 15 & 34 & 15 & 36 & 36 & 36 \\
\hline 6 & p.R133C & 2007 & 49 & 9 & 18 & 10 & 10 & 18 & 9 & 20 & 42 & 19 \\
\hline 7 & p.R133C & 2007 & 56 & 12 & 28 & 36 & 36 & 31 & 30 & 28 & - & 32 \\
\hline 8 & p.R270X & 2007 & 60 & 12 & 18 & 19 & 19 & 24 & 19 & 18 & 18 & 27 \\
\hline 9 & p.R270X & 2008 & 44 & 6 & 15 & 15 & 16 & 15 & 15 & - & 24 & 25 \\
\hline 10 & p.T158M & 2008 & 43 & 14 & 14 & 14 & - & 16 & 12 & 14 & - & 20 \\
\hline 11 & p.T158M & 2009 & 28 & 9 & 10 & 11 & - & 12 & 10 & 10 & - & 20 \\
\hline 12 & $\begin{array}{l}\text { C-terminal } \\
\text { deletion }\end{array}$ & 2007 & 51 & 33 & - & - & - & - & 33 & - & 38 & 42 \\
\hline 13 & p.R106W & 2008 & 43 & 6 & 10 & 10 & 11 & 10 & 13 & 10 & - & 19 \\
\hline 14 & p.R294X & 2008 & 46 & 2 & 36 & 18 & 12 & 36 & 18 & - & - & 25 \\
\hline
\end{tabular}


Table 2: Summary of first identifiable concerns and illustrative quote for each child

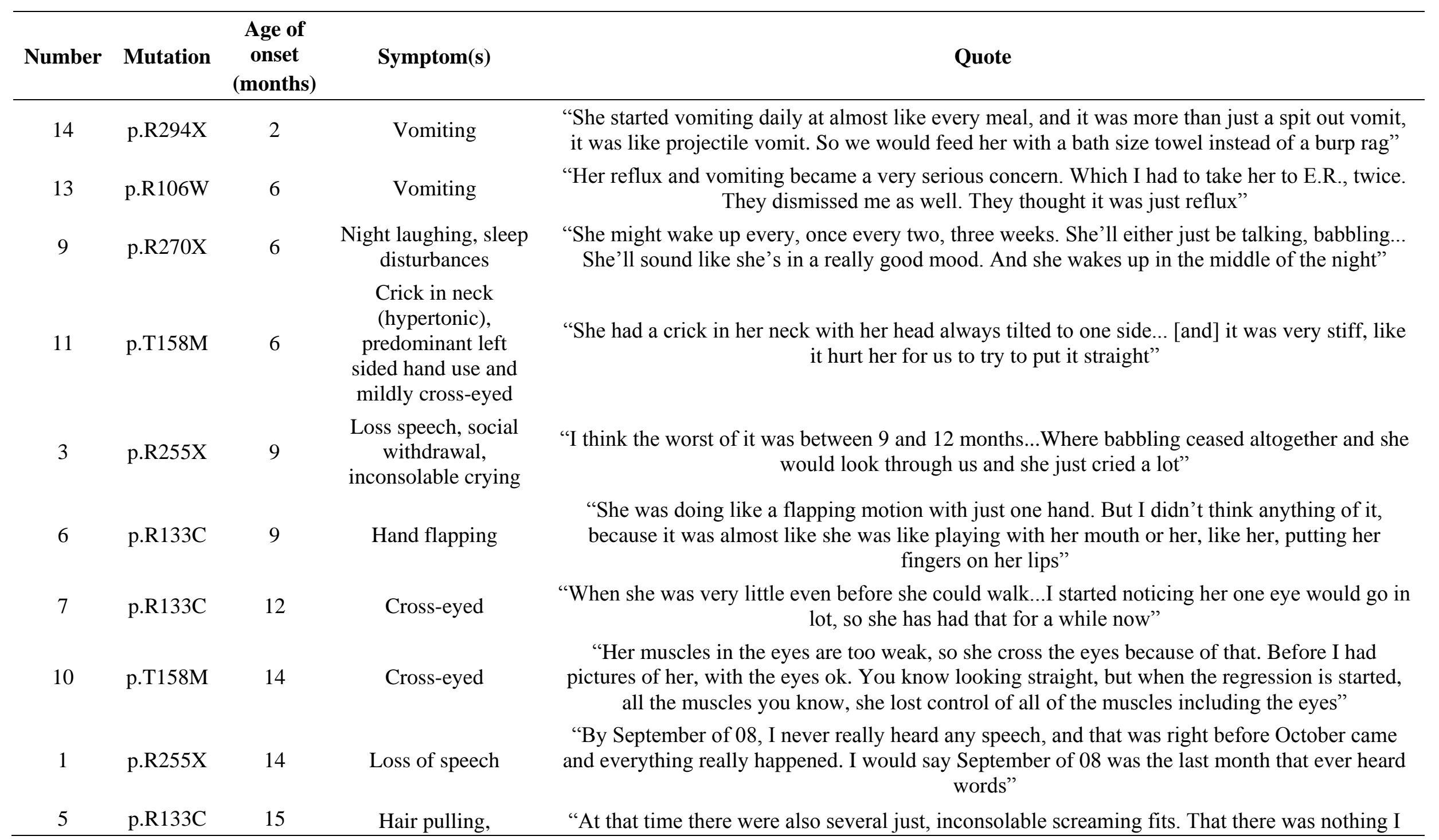




\begin{tabular}{|c|c|c|c|c|}
\hline & & & $\begin{array}{l}\text { inconsolable crying, } \\
\text { sleep disturbances }\end{array}$ & $\begin{array}{c}\text { could do to appease her. So the hair pulling, the screaming fits, the lack of sleep. Those three } \\
\text { things all happened around, like in the spring of 2009" }\end{array}$ \\
\hline 8 & p.R270X & 18 & $\begin{array}{l}\text { Loss of speech, social } \\
\text { withdrawal, } \\
\text { inconsolable crying } \\
\text { and hand stereotypies }\end{array}$ & $\begin{array}{l}\text { “.. she had gotten a lot quieter and sort of wasn't babbling as much. But it was more her eye } \\
\text { contact, she was crying a lot uncontrollably during the night. And yeah, she didn't really want } \\
\text { cuddles, didn't want to look at you and she was sort of like constantly flicking a book a lot. And } \\
\text { carry a hat with her. She always had a hat ... we noticed all that." }\end{array}$ \\
\hline 4 & p.R255X & 18 & Inconsolable crying & $\begin{array}{l}\text { "I mean there are some days when she would have five or six or more in a day. Even now when } \\
\text { she is having a really bad day, sometimes she has four or five, and sometime she doesn't have } \\
\text { any, but I would say most days she has at least a couple" }\end{array}$ \\
\hline 2 & p.R255X & 24 & Loss hand use & $\begin{array}{l}\text { "Before she started school, she was able to grab toys, and like feed herself small finger foods, and } \\
\text { then she started to regress... We are still working on trying to get those skills back. So right now, } \\
\text { she can't self feed herself anymore" }\end{array}$ \\
\hline 12 & $\begin{array}{l}\text { C- } \\
\text { Terminal } \\
\text { deletion }\end{array}$ & 33 & Hand stereotypies & $\begin{array}{c}\text { "She did something where she'd pull on the back of her pants kind of looked like she might need } \\
\text { to use the restroom" }\end{array}$ \\
\hline
\end{tabular}

